\title{
Mercury cycling in the Baltic Sea: can stable isotopes help us?
}

\author{
SYLVAIN BOUCHET ${ }^{1,2}$, ANNE SOERENSEN $^{3}$, ERIK \\ BJÖRN $^{4}$, EMMANUEL TESSIER ${ }^{5}$ AND DAVID \\ AMOUROUX $^{6}$
}

${ }^{1}$ Université de Pau et des Pays de l'Adour, E2S UPPA, CNRS, IPREM, Institut des Sciences Analytiques et de Physico-chimie pour l'Environnement et les matériaux

${ }^{2}$ EAWAG

${ }^{3}$ Swedish Museum of Natural History

${ }^{4}$ Department of Chemistry, Umeå University

${ }^{5}$ Université de Pau et des Pays de l'Adour, E2S UPPA, CNRS, IPREM

${ }^{6}$ CNRS, Université de Pau et Pays de l'Adour, E2S UPPA, IPREM

Presenting Author: sylvain.bouchet@usys.ethz.ch

Mercury $(\mathrm{Hg})$ is a toxic element of global environmental concern, released by both natural and anthropogenic activities. In aquatic and terrestrial ecosystems, $\mathrm{Hg}$ can be converted to monomethylmercury (MMHg), a potent neurotoxin bioaccumulated and bioamplified in food webs. Over the past two decades, research on stable isotopes of $\mathrm{Hg}$ has improved process understanding and sources tracking of $\mathrm{Hg}$ in the environment [1].

The Baltic Sea is a shallow, complex aquatic ecosystem that covers a large range in salinity, redox conditions and microbial activities. It receives substantial inputs of terrestrial $\mathrm{OM}$ and nutrients, which makes it prone to eutrophication and deoxygenation, as well as $\mathrm{Hg}$ and $\mathrm{MMHg}$ inputs from multiple sources [2]. In this work, $\mathrm{Hg}$ concentrations and stable isotopes were determined in sediments, fish and plankton collected from various sub-basins of the Baltic Sea to better elucidate the complex cycling of $\mathrm{Hg}$ in this coastal sea ecosystem. Here, we will discuss $\mathrm{Hg}$ stable isotope variations in perspective of $\mathrm{Hg}$ sources and processes affecting $\mathrm{MMHg}$ production and degradation. Hg stable isotopic composition in sediments $\left(\mathrm{d}^{202} \mathrm{Hg}\right.$ from -2.3 to $-0.1 \%$ ) demonstrates that $\mathrm{Hg}$ in the Baltic Sea results from a rather homogeneous mixing between pre-industrial "background" inputs of $\mathrm{Hg}$ with lighter isotope signature, and recent anthropogenic inputs with heavier signature. Herring populations from the various sub-basins are well discriminated by their mass dependent $\left(\mathrm{d}^{202} \mathrm{Hg}\right.$ from - 0.29 to $0.73 \%$ ) and/or mass-independent fractionation $\left(\mathrm{D}^{199} \mathrm{Hg}\right.$ from 0.33 to $3.04 \%$ ) induced by processes affecting MMHg before its uptake by biota. The $\mathrm{Hg}$ isotopic composition of plankton shows intermediate values between sediments and fish, partly explained by their relative content of $\mathrm{MMHg}$ (average $27 \% \mathrm{HgT}$ ). Overall this study provides insights into the origin and cycling of $\mathrm{MMHg}$ found in pelagic fish that forage in distinct Baltic Sea basins. It demonstrates that the bioaccumulated $\mathrm{MMHg}$ pool originates from variable inputs from terrestrial and/or anoxic waters and undergoes substantial photodegradation.

REFERENCES

[1] Blum et al., Annu. Rev. Earth Planet. Sci. 2014. 42:24969. [2] Soerensen et al., Global Biogeochem. Cycles 2018. 32: 